\title{
Studi Kasus : Penerapan Energy Saving Device dalam Rangka Menaikkan Efisiensi Thrust pada Kapal Tanker Pertamina 40000 Ltdw
}

\author{
Garry Raditya Putra, dan I Ketut Aria Pria Utama \\ Jurusan Teknik Perkapalan, Fakultas Teknologi Kelautan, Institut Teknologi Sepuluh Nopember (ITS) \\ J1. Arief Rahman Hakim, Surabaya 60111 Indonesia \\ e-mail:kutama@na.its.ac.id
}

\begin{abstract}
Abstrak-Energy Saving Devices (ESD) merupakan alat yang berfungsi menekan hambatan gesek yang terjadi pada buritan kapal, sehingga energi yang dikeluarkan oleh mesin kapal tidak mengalami loss energy yang cukup berpengaruh pada konsumsi bahan bakar. Alat ini dipasang di sekitar propeler, yang tujuannya untuk mengurangi kavitasi pada daerah propeler sehingga hambatan yang dialami oleh kapal dapat berkurang. PT. Pertamina (PERSERO) selaku BUMN yang bergerak di bidang minyak dan gas, membutuhkan kapal tanker yang efisien dalam hal konsumsi bahan bakar. Dari kasus ini, kemudian dicari model ESD yang akan dipakai untuk kapal tanker, mengetahui efisiensi dari ESD dan perbandingan hambatan sebelum dan setelah dipasang ESD.
\end{abstract}

Kata Kunci-Energy Saving Devices, ESD, Gaya Dorong, Thrust, Propulsi

\section{PENDAHULUAN}

$\mathrm{K}$ APAL tanker dikenal dengan kapal yang memiliki ukuran cukup besar. Hal ini terjadi karena dengan adanya aturan MARPOL 73/78 Part A Regulation 19 yang mengatur ruang muat kargo pada kapal tanker yang dibangun setelah 6 Juli 1996, dimana harus ditambahkan double hull secara tak langsung mempengaruhi ukuran kapal tanker yang dibangun [1]. Pertamina (PERSERO) selaku BUMN di bidang minyak dan gas, gencar membangun kapal tanker baru untuk meregenerasi kapal tanker yang banyak dibangun pada era 1980 an. Tentunya sebagai owner, Pertamina (PERSERO) menginginkan kapal yang dibangun harus efisien dari bahan bakar kapal yang dikeluarkan. Salah satu cara untuk menekan bahan bakar kapal adalah menggunakan Energy Saving Devices (ESD) [2].

ESD adalah alat pelindung propeler yang berfungsi mengurangi hambatan gesek pada badan kapal sehingga bahan bakar yang dikeluarkan mesin akan efisien. Teknologi ESD ini mulai dikenal pada awal pertengahan abad 20 dan populer pada akhir tahun 1970-an dan awal tahun 1980-an saat terjadinya krisis minyak di dunia [3]. Banyak desain alat ini yang berkembang dan sebagian besar diantaranya tidak cocok untuk digunakan pada kapal saat awal inovasi ini muncul. Dengan beberapa alat ini yang tidak diterima di kapal, tentu ada alasan yang membuat alat ini tidak dipakai di kapal. Di antaranya karena masih adanya kegagalan konstruksi pada ESD, adanya cacat pada pembuatan ESD hingga terbatasnya desain ESD yang tak memungkinkan dipasang di kapal ukuran tertentu. Namun seiring berjalannya waktu, pengembangan ESD ini dapat diterima di hampir semua jenis kapal [4]. Aplikasi ESD ini dapat menekan kerugian yang timbul dari desain stern kapal yang dibangun. Di antaranya mengurangi hambatan gesek pada aliran yang mengalir di propeler dan badan kapal, dan mengurangi kehilangan gaya dorong propeler atau propeler loss [5].

Di Indonesia, baru beberapa kapal yang menerapkan aplikasi ESD ini. Salah satunya adalah PT. Pertamina (PERSERO) dengan kapal tanker 40000 LTDW. Dengan adanya inovasi di bidang perkapalan ini, PT. Pertamina (PERSERO) tak ingin tertinggal dalam menerapkan inovasi ini agar kapal milik mereka bisa efisien dari tenaga mesin yang tak terlalu besar namun gaya dorong yang dihasilkan mesin bisa memutar propeler agar kapal bisa berjalan [2]

Berdasarkan penelitian terdahulu, kapal yang menggunakan aplikasi ESD dapat menghasilkan efisiensi hingga 7\% pada kapal tertentu. Hal ini tentu dapat dilakukan juga pada kapal tanker Pertamina, yang ingin menghasilkan efisiensi yang cukup besar nilainya. Sehingga energi yang terbuang dari thrust, bisa digunakan kembali sebagai energi kapalnya. [6]

\section{METODE PENELITIAN}

Pada bagian ini, diterangkan mengenai metode yang penulis lakukan dari nol sampai Penelitian ini berhasil diselesaikan. Penulis menjabarkannya dengan menggunakan flowchart. Metode penelitian yang dijabarkan pada bagan berikut.

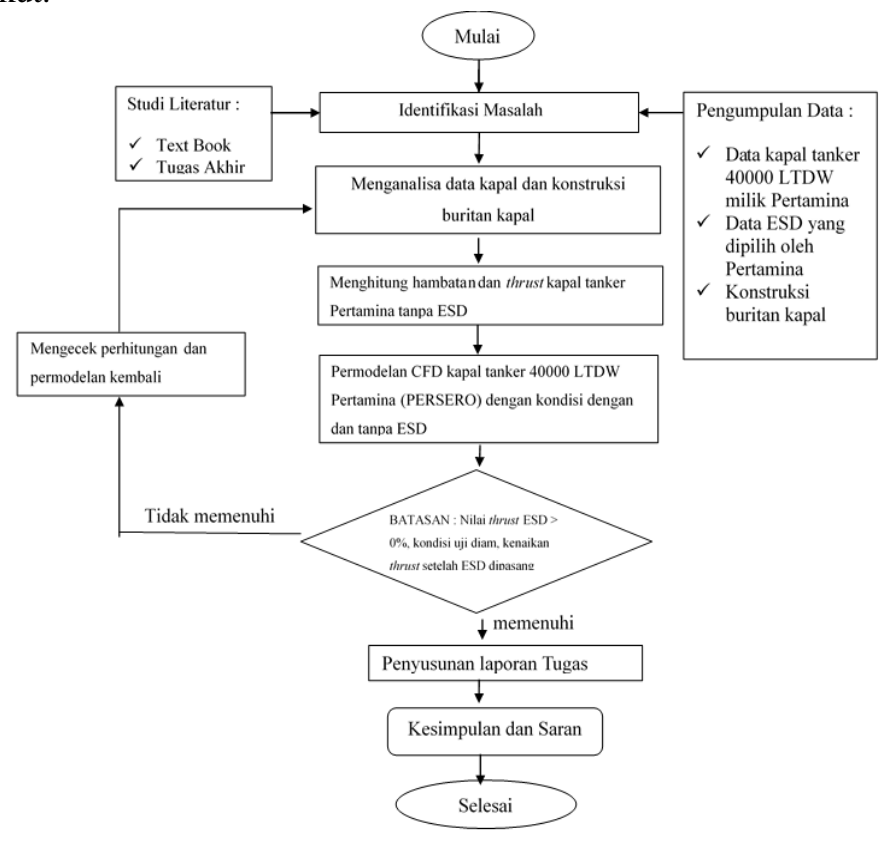

Gambar 1. Diagram alir metode penelitian

Dalam penelitian ini, langkah pertama yang penulis lakukan adalah mengidentifikasi masalah. Penelitian ini meneliti tentang besarnya efisiensi yang terjadi karena 
adanya Energy Saving Devices (ESD) yang dipasang oleh PT. Pertamina (PERSERO) Perkapalan pada kapal tanker 40000 LTDW. Maka dari itu, penulis membutuhkan data berupa literatur penelitian yang memiliki topik yang serupa dan text book yang berkaitan dengan masalah propulsi dan hidrodinamika. Selain itu, data-data kapal tanker 40000 LTDW dari PT. Pertamina (PERSERO) Perkapalan juga dibutuhkan. Data kapal penelitian ini dijabarkan pada Tabel 1 .

Tabel 1. Data kapal dan model dari tanker Pertamina (PERSERO) 40000 LTDW

\begin{tabular}{|c|c|c|c|c|}
\hline Nama & Simbol & Satuan & Kapal & Model \\
\hline $\begin{array}{c}\text { Length } \\
\text { Overall }\end{array}$ & LoA & $\mathrm{m}$ & 183.000 & 3.9262 \\
\hline $\begin{array}{c}\text { Length } \\
\text { between } \\
\text { perpendicular }\end{array}$ & Lpp & $\mathrm{m}$ & 175.500 & 3.7653 \\
\hline Breadth & $\mathrm{B}$ & $\mathrm{m}$ & 32.500 & 0.6973 \\
\hline Depth & $\mathrm{D}$ & $\mathrm{m}$ & 17.100 & 0.3669 \\
\hline Draft & $\mathrm{T}$ & $\mathrm{m}$ & 11.000 & 0.2360 \\
\hline Displacement & $\nabla$ & ton & 51181.000 & 0.5054 \\
\hline Volume & $\Delta$ & $\mathrm{m}^{3}$ & 49932.683 & 0.4931 \\
\hline
\end{tabular}

Langkah berikutnya adalah menghitung hambatan kapal kosong. Metode yang dipakai adalah metode Holtrop, karena metode ini cukup efektif dalam mencari nilai hambatan kapal, dan juga karena koefisien dari metode ini mudah dicari [7]. Setelah dari perhitungan hambatan kapal kosong, kemudian penulis melakukan permodelan terhadap kapal tanker Pertamina (PERSERO) ini. Untuk data hambatan serta koefisien propulsi dijabarkan pada Tabel 2 dan Tabel 3 :

Tabel 2. Data hambatan kapal tanker Pertamina (PERSERO) 40000 LTDW

\begin{tabular}{|c|c|c|c|}
\hline Item & $\mathbf{V}=\mathbf{1 0}$ knot & $\begin{array}{c}\mathbf{V}=15 \text { knot } \\
\text { (Service Speed) }\end{array}$ & $\mathbf{V}=18$ knot \\
\hline Froude Number $(\mathrm{Fn})$ & 0,122 & 0,182 & 0,182 \\
\hline Koefisien Gesek (CF) & 0,00158 & 0,00150 & 0,00147 \\
\hline $\begin{array}{c}\text { Model }- \text { Ship Correction } \\
\text { Allowance }\left(\mathrm{C}_{\mathrm{A}}\right)\end{array}$ & 0,000382111 & 0,000382111 & 0,000382111 \\
\hline Wake Fraction (w) & 0,158 & 0,157 & 0,157 \\
\hline Hambatan Total (RT) & $282,098 \mathrm{KN}$ & $720,315 \mathrm{KN}$ & $1369,776 \mathrm{KN}$ \\
\hline $\begin{array}{c}\text { Effective Horse Power } \\
\text { (EHP) }\end{array}$ & $1972,962 \mathrm{HP}$ & $7556,692 \mathrm{HP}$ & $17244,089 \mathrm{HP}$ \\
\hline $\begin{array}{c}\text { Delivered Horse Power } \\
\text { (DHP) }\end{array}$ & $3284,22 \mathrm{HP}$ & $10828,35 \mathrm{HP}$ & $24720,04 \mathrm{HP}$ \\
\hline \begin{tabular}{c} 
Shaft Horse Power (SHP) \\
\hline Brake Horse Power (BHP)
\end{tabular} & $3351,24 \mathrm{HP}$ & $11049,34 \mathrm{HP}$ & $25224,53 \mathrm{HP}$ \\
\hline Speed of Advance (Va) & $8,42 \mathrm{knot}$ & $12,64 \mathrm{knot}$ & $15,17 \mathrm{knot}$ \\
\hline \hline
\end{tabular}

Tabel 3. Data koefisien propulsi kapal tanker Pertamina (PERSERO) 40000 LTDW

\begin{tabular}{|c|c|c|c|}
\hline Item & $\mathbf{V = 1 0}$ knot & $\begin{array}{c}\mathbf{V}=15 \text { knot } \\
\text { (Service Speed) }\end{array}$ & $\mathbf{V = 1 8 ~ k n o t}$ \\
\hline Jumlah daun Propeler $(\mathrm{Z})$ & 4 & 4 & 4 \\
\hline Propeler Disc Area $\left(\mathrm{A}_{0}\right)$ & $34,266 \mathrm{~m}^{2}$ & $34,266 \mathrm{~m}^{2}$ & $34,266 \mathrm{~m}^{2}$ \\
\hline Diameter Propeler $(\mathrm{D})$ & $6,60 \mathrm{~m}$ & $6,60 \mathrm{~m}$ & $6,60 \mathrm{~m}$ \\
\hline Hambatan total $(\mathrm{RT})$ & $282,098 \mathrm{KN}$ & $720,315 \mathrm{KN}$ & $1369,776 \mathrm{KN}$ \\
\hline Speed of Advance $(\mathrm{Va})$ & $8,42 \mathrm{knot}$ & $12,64 \mathrm{knot}$ & $15,17 \mathrm{knot}$ \\
\hline Massa jenis air laut $(\rho)$ & $1,025 \mathrm{ton} / \mathrm{m}^{3}$ & $1,025 \mathrm{ton} / \mathrm{m}^{3}$ & 1,025 ton $/ \mathrm{m}^{3}$ \\
\hline Thrust dari hambatan total $(\mathrm{kN})$ & 328,021 & 837,575 & 1592,762 \\
\hline Koefisien gaya dorong $(\mathrm{CTh})$ & 0,997 & 1,130 & 1,491 \\
\hline
\end{tabular}

Berdasarkan hasil koefisien gaya dorong yang penulis dapat, dengan data yang diklaim dari Becker TM selaku perusahaan yang menyediakan ESD pada kapal tanker Pertamina 40000 LTDW ini, diperkirakan nilai efisiensi dari ESD akan bernilai $3 \%$ pada Vs $=10$ knot, 3,5\% pada $\mathrm{Vs}=15$ knot dan $4 \%$ pada Vs $=18$ knot. [8].

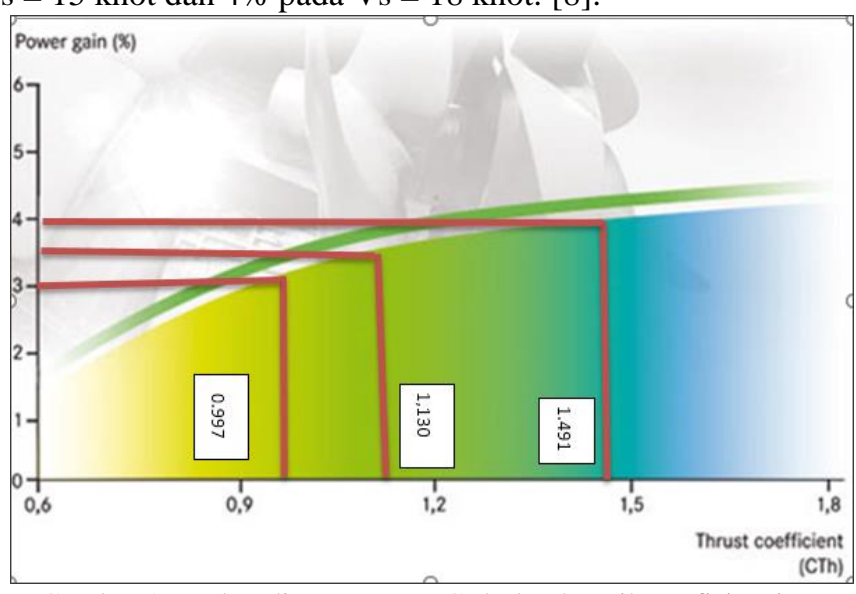

Gambar 2. Perbandingan antara CTh dan kenaikan efisiensi energi.

Penelitian ini menggunakan perhitungan dengan metode Computational Fluid Dynamics (CFD) [9]. Metode ini dibutuhkan permodelan, running, dan visualisasi hasil. Pada tahap permodelan, data linesplan kapal dibutuhkan untuk proses penggambaran ulang atau redrawing dari badan kapal. Aplikasi yang digunakan adalah Autodesk AutoCAD 2014 trial version. Setelah badan kapal selesai digambar ulang, maka tahap berikutnya adalah memodelkan propeler dan ESD. ESD yang digunakan oleh PT. Pertamina (PERSERO) ini adalah Becker тM Twisted Fins. Untuk memodelkan propeler, penulis memakai aplikasi HydroComp PropCAD 2005. Setelah data dibuat dari PropCAD, data tadi diekspor ke AutoCAD untuk dilakukan perbaikan. Sedangkan permodelan ESD dilakukan dengan aplikasi Autodesk AutoCAD 2014 trial version yang dibantu juga dengan aplikasi SolidWorks 2015 SP 3.0. Hal ini dilakukan untuk memastikan ESD yang dibuat bisa presisi dengan badan kapal dan propeler.

Tahapan berikutnya adalah membuat permodelan dengan aplikasi ANSYS ICEM CFD v.14.5 dan running dengan aplikasi ANSYS CFX v.14.5. Pertama adalah membuka file dari permodelan kapal, ESD dan propeler yang sudah dibuat sebelumnya ke ANSYS ICEM CFD v.14.5. Kemudian buat 
permukaan (surface) dari masing-masing model tadi. Setelah dibuat permukaan, maka buat elemen-elemen dari model atau meshing, sehingga dari model ini bisa dibuat analisa secara hidrodinamika dari model.

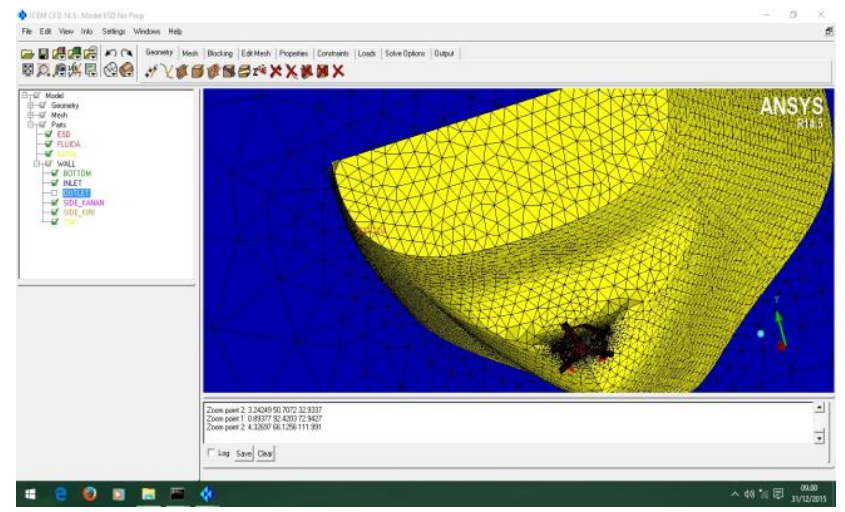

Gambar 3. Meshing dengan ANSYS ICEM CFD

Setelah dilakukan proses meshing, file bisa langsung diekspor ke ANSYS CFX. Ada 3 aplikasi yang digunakan, yaitu ANSYS Pre, ANSYS Solver, dan ANSYS Post. ANSYS Pre berfungsi untuk memasukan batasan yang akan dilakukan sebelum dilakukan running, ANSYS Solver berfungsi untuk melakukan proses running dan ANSYS Post berfungsi untuk melakukan analisa setelah file dirunning. Untuk tahap yang dilakukan penulis dalam proses running adalah :

- Pertama, buka aplikasi ANSYS CFX di komputer

\section{- Pilih ANSYS Pre pada menu}

- Lalu buat projek baru dengan cara File - New Kasus General - Ok.

- Kemudian pilih Import - Mesh. Pilih file mesh ICEM CFD yang telah disimpan sebelumnya. Kemudian pilih open.

- Akan tampil meshing yang sudah dilakukan di ICEM CFD sebelumnya.

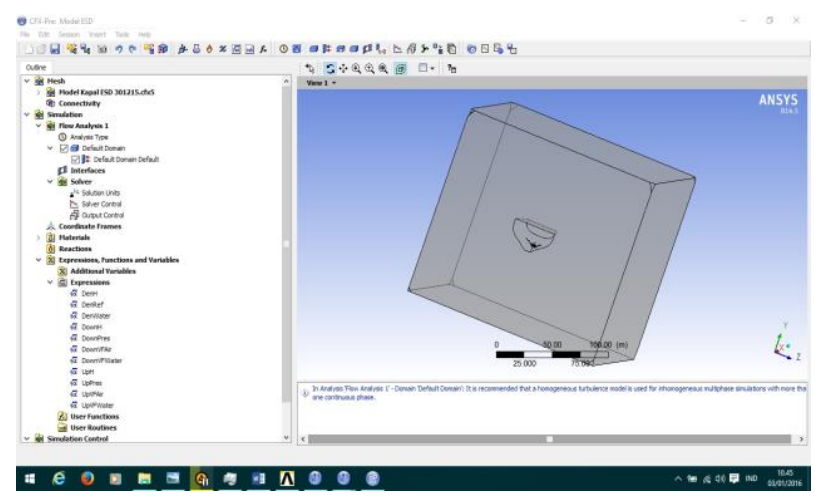

Gambar 4. Tampilan awal CFX Pre dari permodelan

- Kemudian dimasukkan kondisi batas pada analisa ini. Untuk analisa ini, penulis membatasi kondisi : propeler dalam analisa ini dalam keadaan fixed mesh. Lalu diuji dalam keadaan dua kondisi, kapal dengan menggunakan ESD dan kapal tanpa menggunakan ESD dengan tiga variasi kecepatan, yaitu 10 knot, 15 knot dan 18 knot.

- Masukan batasan-batasan ini, beserta persamaan kendali kasus di jendela domain di kiri layar aplikasi. Batasan yang dimasukkan di antaranya :

a. Persamaan kontinuitas yang memiliki rumus :

$$
\begin{aligned}
& \dot{\mathrm{m}}_{\text {inlet }}=\dot{\mathrm{m}}_{\text {outlet }} \\
& (\rho \mathrm{Av})_{\text {inlet }}=(\rho \mathrm{Av})_{\text {outlet }}
\end{aligned}
$$

b. Persamaan Navier-Stokes yang memiliki rumus :

$$
\rho\left(\frac{\partial \mathbf{v}}{\partial t}+\mathbf{v} \cdot \nabla \mathbf{v}\right)=-\nabla p+\nabla \cdot \mathbf{T}+\mathbf{f},
$$

c. Persamaan turbulence model pada kasus, dimana penulis memakai metode $k$-epsilon. Metode ini memiliki rumus :

$$
\mu_{t}=\rho C_{\mu} \frac{k^{2}}{\epsilon}
$$

- Kemudian setelah selesai, dapat dilakukan simulasi running dengan ANSYS Solver.

Tahapan berikutnya adalah tahap iterasi atau running. Proses iterasi adalah proses penghitungan kasus yang dibuat dengan menggunakan perhitungan komputer, sehingga nantinya akan didapat hasil perhitungan yang telah dimasukan pada aplikasi ANSYS Pre. Hasil dari iterasi ini bisa dicari dengan menggunakan aplikasi ANSYS Post. Pada penelitian ini, penulis ingin mengetahui hasil kenaikan thrust pada masing-masing kasus. Sehingga yang dicari pada ANSYS Post berupa gaya tekan yang bekerja sesuai kecepatan kapal. Pada kasus penelitian ini, penulis merekap komputasi dan waktu yang diperlukan dalam melakukan proses running. Hal ini untuk mengetahui berapa lama pengujian grid independent yang dibutuhkan pada kasus pengujian penulis, sehingga pembaca dapat mengerti bahwa

\begin{tabular}{|c|c|c|c|}
\hline Nama & Kasus & Spesifikasi & Waktu Iterasi \\
\hline \multirow[t]{4}{*}{$\begin{array}{l}\text { Lenovo } \\
\text { H50-50 }\end{array}$} & $\begin{array}{c}\text { ESD \& } \\
\text { Propeler } \\
\text { dengan Vs } \\
=10 \mathrm{knot}\end{array}$ & $\begin{array}{c}\text { RAM } 8 \text { GB, Intel Core i5 3rd } \\
\text { Gen, HDD } 1 \text { TB } \\
\text { Grid Independent }=800000 \\
\text { Max iteration }=900\end{array}$ & $\begin{array}{c}4 \text { jam } 27 \text { menit } \\
47 \text { detik }\end{array}$ \\
\hline & $\begin{array}{c}\text { ESD \& } \\
\text { Propeler } \\
\text { dengan Vs } \\
=15 \mathrm{knot} \\
\end{array}$ & $\begin{array}{c}\text { RAM } 8 \text { GB, Intel Core i5 3rd } \\
\text { Gen, HDD } 1 \text { TB } \\
\text { Grid Independent }=800000 \\
\text { Max iteration }=900\end{array}$ & $\begin{array}{c}4 \text { jam } 34 \text { menit } \\
11 \text { detik }\end{array}$ \\
\hline & $\begin{array}{l}\text { ESD \& } \\
\text { Propeler } \\
\text { dengan Vs } \\
=18 \mathrm{knot}\end{array}$ & $\begin{array}{l}\text { RAM } 8 \text { GB, Intel Core i5 3rd } \\
\text { Gen, HDD } 1 \text { TB } \\
\text { Grid Independent }=800000 \\
\text { Max iteration }=900\end{array}$ & $\begin{array}{c}4 \text { jam } 35 \text { menit } \\
5 \text { detik }\end{array}$ \\
\hline & $\begin{array}{l}\text { Propeler } \\
\text { dengan Vs } \\
=18 \mathrm{knot}\end{array}$ & $\begin{array}{l}\text { RAM } 8 \text { GB, Intel Core i5 3rd } \\
\text { Gen, HDD } 1 \text { TB } \\
\text { Grid Independent }=800000 \\
\text { Max iteration }=900\end{array}$ & $\begin{array}{c}4 \text { jam } 29 \text { menit } \\
5 \text { detik }\end{array}$ \\
\hline \multirow[t]{2}{*}{$\begin{array}{c}\text { Asus } \\
\text { X450JN }\end{array}$} & $\begin{array}{l}\text { Propeler } \\
\text { dengan Vs } \\
=10 \text { knot }\end{array}$ & $\begin{array}{l}\text { RAM } 4 \text { GB, Intel Core i7 3rd } \\
\text { Gen, HDD } 1 \text { TB } \\
\text { Grid Independent }=800000 \\
\text { Max iteration }=900\end{array}$ & $\begin{array}{l}6 \text { jam } 51 \text { menit } \\
33 \text { detik }\end{array}$ \\
\hline & $\begin{array}{l}\text { Propeler } \\
\text { dengan Vs } \\
=15 \text { knot }\end{array}$ & $\begin{array}{c}\text { RAM } 4 \text { GB, Intel Core i7 3rd } \\
\text { Gen, HDD } 1 \text { TB } \\
\text { Grid Independent }=800000 \\
\text { Max iteration }=900\end{array}$ & 7 jam 44 detik \\
\hline
\end{tabular}
penelitian ini membutuhkan jam orang yang banyak. Tabulasi dari proses running ini dijabarkan pada Tabel 4.

Tabel 4.Data komputasi dan waktu iterasi komputer penelitian 


\section{HASIL DAN DISKUSI}

Berdasarkan langkah pekerjaan pada bagian sebelumnya, setelah dilakukan iterasi dengan ANSYS Solver, maka tabulasi gaya tekan yang menekan daun propeler dijabarkan pada Tabel 5 berikut

Tabel 5. Hasil gaya tekan propeler pada semua kondisi uji model dengan function calculator ANSYS Post

\begin{tabular}{|c|c|c|c|c|c|c|}
\hline Keadaan & $\begin{array}{c}\text { Propeler } \\
18 \mathrm{knot}\end{array}$ & $\begin{array}{r}\text { Propeler } \\
15 \mathrm{knot}\end{array}$ & $\begin{array}{c}\text { Propeler } \\
10 \mathrm{knot}\end{array}$ & $\begin{array}{c}\text { Propeler } \\
\& \text { ESD } \\
18 \mathrm{knot}\end{array}$ & $\begin{array}{c}\text { Propeler } \\
\& \text { ESD } \\
15 \mathrm{knot}\end{array}$ & $\begin{array}{c}\text { Propeler \& } \\
\text { ESD 10 } \\
\text { knot }\end{array}$ \\
\hline $\begin{array}{c}\text { Gaya tekan } \\
(\mathrm{N})\end{array}$ & 352.746 & 244.312 & 109.864 & 324.358 & 224.715 & 99.285 \\
\hline
\end{tabular}

Dari data di atas, dapat disimpulkan bahwa pada saat ESD terpasang, gaya tekan pada propeler mengalami penurunan. Hal itu bisa terjadi karena sebagian gaya tekan terdistribusi ke ESD, yang mengarahkan aliran air menjadi teratur, sehingga gaya yang bekerja berkurang. Selisih antara gaya tekan ini dinamakan gain. Di mana rumusnya adalah : $352.746-324.358=28.388 \mathrm{~N}$ atau $28,388 \mathrm{kN}$ untuk kecepatan kapal $(\mathrm{Vs})=18$ knot dan 244.312 $224.715=19.597 \mathrm{~N}$ atau $19,597 \mathrm{kN}$ untuk kecepatan kapal $(\mathrm{Vs})=15$ knot serta $109.864-99.285=10.579 \mathrm{~N}$ atau $10,579 \mathrm{kN}$ untuk kecepatan kapal $(\mathrm{Vs})=10$ knot. Serta berdasarkan perhitungan hambatan yang mendapatkan nilai service thrust pada kapal ini sebesar $837,575 \mathrm{kN}$, maka berdasarkan rumus di awal, bisa dicari efisiensi dari thrust kapal ini.

$$
\begin{aligned}
& \text { Eff. Gained }=\frac{\text { Gain }}{\text { Service thrust }} * 100 \%=\frac{10,579}{927,575} * 100 \% \\
& =1,26 \% \text { untuk } \mathrm{Vs}=10 \mathrm{knot} \\
& \text { Eff. Gained }=\frac{\text { Gain }}{\text { Service thrust }} * 100 \%=\frac{19,597}{927,575} * 100 \% \\
& =2,34 \% \text { untuk Vs }=15 \text { knot } \\
& \text { Eff. Gained }=\frac{\text { Gain }}{\text { Service thrust }} * 100 \%=\frac{28_{2} \text { ags }}{287,575} * 100 \% \\
& =3,39 \% \text { untuk } \mathrm{Vs}=18 \mathrm{knot}
\end{aligned}
$$

Untuk membandingkan dengan klaim dari Becker TM pada kapal Pertamina (PERSERO) ini, memiliki efisiensi ESD seperti berikut :

Tabel 6. Persentase efisiensi ESD berdasarkan klaim Becker $^{\mathrm{TM}}$

\begin{tabular}{|c|c|c|c|}
\hline Kecepatan (knot) & $\begin{array}{c}10 \\
\text { knot }\end{array}$ & $\begin{array}{c}15 \\
\text { knot }\end{array}$ & $\begin{array}{c}18 \\
\text { knot }\end{array}$ \\
\hline $\begin{array}{c}\text { Persentase efisiensi berdasarkan } \\
\text { koefisien } \text { thrust (CTh) }\end{array}$ & $3 \%$ & $3,5 \%$ & $4 \%$ \\
\hline
\end{tabular}

Dan ini adalah plot grafik perbandingan antara efisiensi dari perhitungan CFX dan klaim Becker TM.

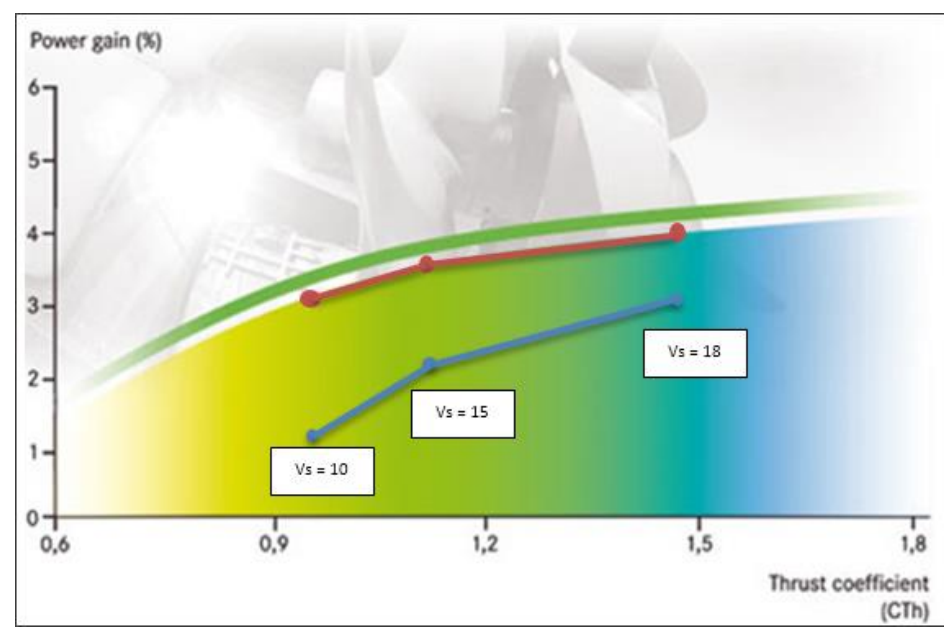

Gambar 5. Plot grafik klaim Becker (merah) dan persentase dari CFX (biru)

Setelah dilakukan perhitungan, maka penulis dapat menganalisa gaya tekan pada propeler. Fungsinya adalah untuk mengetahui distribusi dari persebaran tekanan air terhadap daun propeler yang diuji. Ini adalah grafik dari propeler yang terkena gaya tekan setelah dilakukan iterasi.

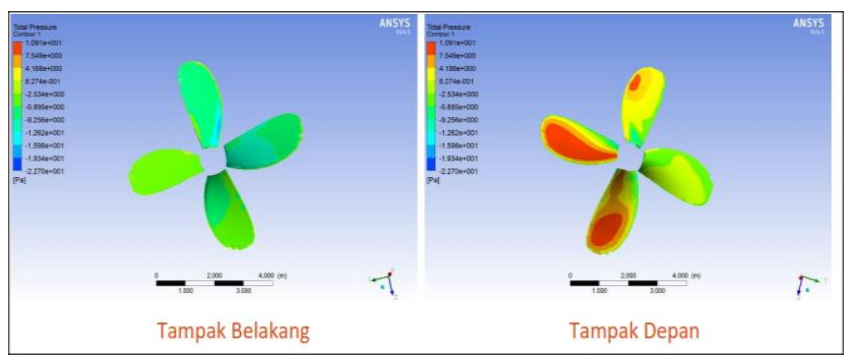

Gambar 6. Gaya tekan pada propeler yang terpasang ESD dengan kecepatan 10 knot

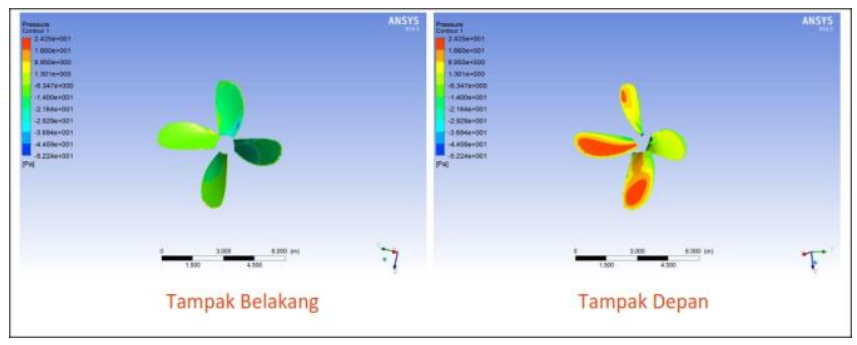

Gambar 7. Gaya tekan pada propeler yang terpasang ESD dengan kecepatan 15 knot

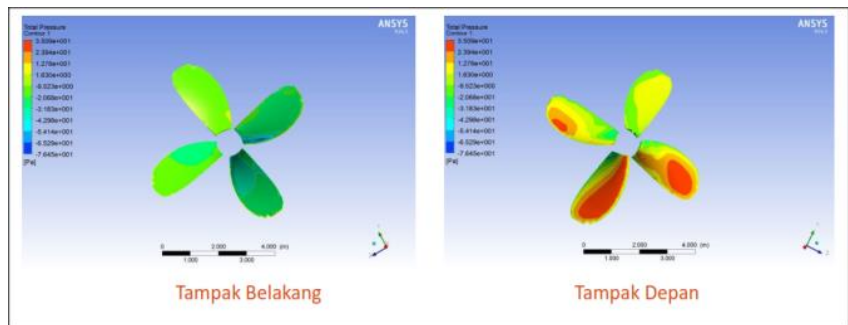

Gambar 8. Gaya tekan pada propeler yang terpasang ESD dengan kecepatan 18 knot 


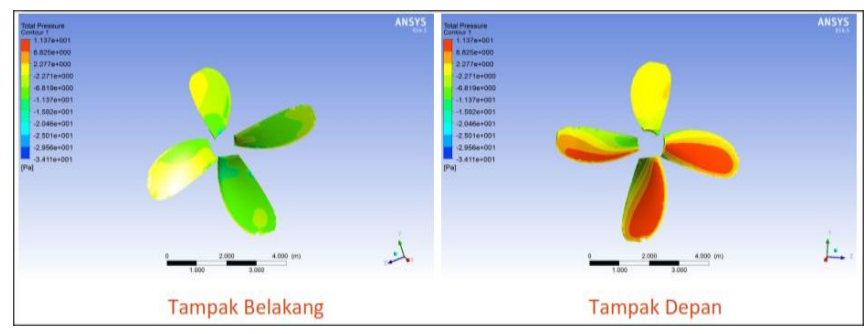

Gambar 9. Gaya tekan pada propeler yang tidak dipasang ESD dengan kecepatan 10 knot

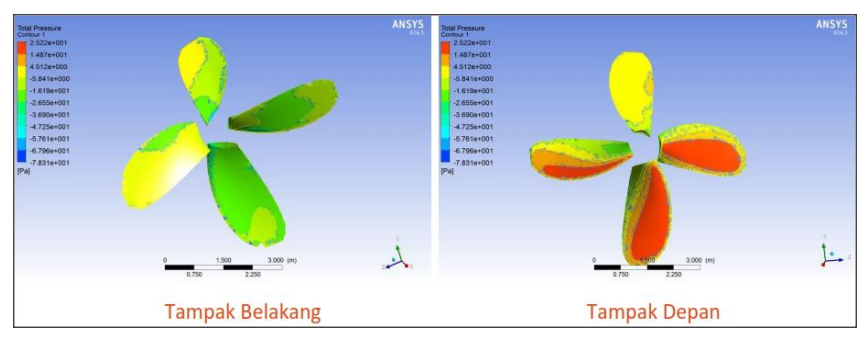

Gambar 10. Gaya tekan pada propeler yang tidak dipasang ESD dengan kecepatan 15 knot

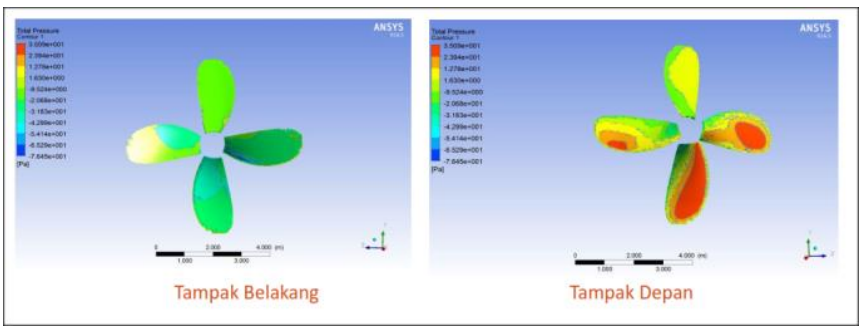

Gambar 11. Gaya tekan pada propeler yang tidak dipasang ESD dengan kecepatan 18 knot

Maka, efisiensi thrust yang terjadi pada saat kapal berlayar dengan kecepatan 18 knot adalah 3,39\%, pada kecepatan dinasnya memiliki efisiensi sebesar 2,34\%, dan untuk kecepatan 10 knot, efisiensi thrust dihasilkan sebesar 1,26\%. Meski tak sama dengan klaim dari Becker $^{\mathrm{TM}}$, hasil ini sudah cukup membuktikan bahwa Pertamina (PERSERO) melakukan langkah yang tepat dalam berinvestasi memasang ESD pada kapal tanker 40000 LTDW milik mereka. Nilai dari klaim ini bisa berbeda karena penulis hanya memodelkan bagian buritan kapal saja, atas dasar keterbatasan waktu dan komputasi penulis. Selain itu, kecepatan akan mempengaruhi nilai efisiensi dari ESD. Hal ini karena semakin cepat kapal berjalan, maka gaya tekan yang menghantam daun propeler kapal akan besar. Sehingga jika ESD dipasang pada kapal yang berjalan lambat, maka nilainya relatif kecil dan bahkan bisa tidak menghasilkan efisiensi. Maka dari itu, faktor bentuk lambung kapal, dan kecepatan kapal sangat dibutuhkan pada saat memilih ESD yang akan dipasang ke kapal.

Untuk persebaran gaya tekan pada propeler, pada kecepatan yang rendah, permukaan daun propeler akan mengalami tekanan fluida lebih banyak. Sehingga, pada bagian tertentu, akan muncul daerah kritis yang ditunjukan dengan warna merah pada Gambar 6 hingga Gambar 11. Selain kecepatan yang rendah, dipasangnya ESD dapat menimbulkan gaya tekan pada daun propeler.
Ini disebabkan karena fluida yang berada diantara propeler dan ESD, akan menekan propeler. Sehingga, pada Gambar 7 sampai Gambar 9, permukaan daun propeler akan tampak bagian yang berwarna jingga, di mana tekanan yang dialami propeler bernilai sedang.

\section{KESIMPULAN \& SARAN}

Kesimpulan dari pembahasan penelitian ini, dapat disimpulkan :

- PT. Pertamina (PERSERO) melakukan langkah tepat dengan memasang ESD pada kapal tankernya

- Permodelan CFX membuktikan adanya efisiensi dari thrust, meski tak sama dengan klaim

- Kecepatan dinas kapal akan mempengaruhi besar kecilnya efisiensi dari ESD.

- Nilai efisiensi yang didapat penulis memiliki perbedaan dikarenakan tidak menguji dengan metode towing tank. Penulis hanya menguji dengan iterasi komputer.

Saran dari penelitian ini, penulis memberikan saran kepada beberapa pihak. Saran untuk PT. Pertamina (PERSERO) Perkapalan adalah :

- Sejalan dengan kebijakan green ship yang dilakukan IMO, maka PT.Pertamina (PERSERO) bisa memperbanyak kapal yang dirasa menguntungkan dari sisi investasi untuk dipasang ESD. Hal ini agar kapal dapat menggunakan putaran mesin rendah dengan tenaga yang cukup besar agar emisi gas buang sedikit yang bisa membuat ramah lingkungan.

- Memvariasikan model ESD dari kapal milik Pertamina (Persero) agar kedepannya dapat menjadi sarana ilmu pengetahuan dan sarana riset di Indonesia.

Serta untuk saran kepada yang ingin mengembangkan tugas akhir penulis adalah :

- Dapat memvariasikan kecepatan selain dua kecepatan yang penulis ambil contohnya.

- Dapat memvariasikan model ESD yang lainnya. Karena model ESD yang berbeda, bisa membuat nilai efisiensi thrust yang ditimbulkan berbeda-beda.

- Jika menggunakan model ESD Becker ${ }^{\mathrm{TM}}$ Twisted Fins dapat divariasikan jarak antara propeler dan ESD nya.

\section{UCAPAN TERIMA KASIH}

"Penulis G.R.P mengucapkan terima kasih kepada PT. Pertamina (PERSERO) Shipping selaku instansi dari penelitian penulis yang senantiasa memberikan kemudahan dalam pemberian data, sdr. Sutiyo yang berjasa pada proses permodelan CFD, dan pihak-pihak yang tak bisa penulis sebutkan satu persatu dalam kesuksesan penulisan penelitian ini." 


\section{DAFTAR PUSTAKA}

[1] Lewis, Edward V. 1980. Principles of Naval Architecture Second Revision, Volume II, Resistance, Propulsion and Vibration. Jersey City, NJ : The Society of Naval Architects \& Marine Engineers.

[2] Data-data kapal, propulsi dan ESD oleh Pertamina (PERSERO) Shipping. Jakarta, Indonesia.

[3] Jong, J. H. D. 2015. A Framework for Energy Saving Devices (ESD) Decision Making, Netherland: MARIN

[4] Holtrop, J., Mennen, G.G.J. 1982. An Approximate Power Prediction Method, International Shipbuilding Progress : Vol. 29, Netherland

[5] Schneekluth, H and V. Bertram. 1998. Ship Design Efficiency and Economy, Second Edition, Oxford, UK : Butterworth Heinemann.

[6] Leksono, Setyo. 2014. Disertasi Pemanfaatan Aliran Slipstream Di Belakang Propeler Kapal Sebagai Energi Penggerak Turbin. Surabaya, Indonesia : ITS

[7] Harvald, Sv., Aa. . 1992. Diktat Tahanan dan Propulsi Kapal, Surabaya. Indonesia : Airlangga University Press

[8] http://www.becker-marinesystems.com/03_products/products_twisted_fin.html Diakses 17 November 2015 jam 10.38 .43

[9] Munson, B.R. Young, D.F. \& Okiishi T.H. 2002. Fluid Mechanics. USA : Departements of Mechanical Engineriing - Iowa State University 